\title{
The Role of Thiamine in Wilson’s Disease: Possible Genetic and Cellular Signaling Mechanisms
}

\author{
Khanh vinh quoc Lương*and Lan Thi Hoang Nguyen
}

Vietnamese American Medical Research Foundation, Westminster, California, USA

\begin{abstract}
The relationship between supplemental thiamine and Wilson's disease has been the focus of recent investigation; and supplemental thiamine has been reported to modulate Wilson's disease. Genetic studies have helped identify a number of factors that link thiamine to Wilson's disease, including transcription factor p53, Bcl-2, caspase-2, heme oxygenase-1, and apolipo protein E. Thiamine has also been implicated in Wilson's disease through its effects on serotonin, reactive oxygen species, and nitric oxide synthase. Therefore, further investigations of thiamine in Wilson's disease are needed to clarify this relationship.
\end{abstract}

Keywords: Thiamine; Wilson's disease; Vitamin B1; Transketolase; Copper toxicity

\section{Introduction}

Copper is an essential trace element that is required for the function of enzymes, including cytochrome $c$ oxidase, superoxide dismutase, dopamine $\beta$-hydroxylase, lysyl oxidase, and ceruloplasmin. Disturbances in copper hemostasis result in cell death in the liver and the Central Nervous System (CNS) in Wilson's disease [1]. During the course of Wilson's disease, copper accumulates equally in different parts of the brain compared with control subjects [2]. Copper ions may directly stimulate the proliferation of hepatic stellate cells via oxidative stress [3]. The relationship between thiamine and copper was reported in the literature. A low serum ceruloplasmin concentration is considered diagnostic for Wilson's disease [4]. The serum ceruloplasmin level, which serves as a marker of copper metabolism, is also decreased in Thiamine-Deficient (TD) animals [5]. Copper can cause thiamine to be oxidized to the fluorescent products thiochrome and oxodihydrothiochrome in neutral and acidic media [6]. Copper also induces neuronal death in murine neocortical cell cultures; the addition of thiamine to the drinking water of an animal model with Wilson's disease markedly extends the animal's life span from 6 months to greater than 16 months [7]. Copper induces proteotoxic effects, inflammatory reactions/oxidative stress, growth arrest, and DNA damage in human liver carcinoma cells [8]. Hepatic copper accumulation significantly increases the risk of cancerous neoplasms both in humans and rats [9]. However, oral thiamine supplementation attenuates Wilson's diseaseinduced hepatocellular carcinoma [10]. In addition, copper overload induces lipid peroxidation, the formation of 4-hydroxy-nonenal (HNE), and mitochondrial dysfunction in rats [11]. HNE inhibits Pyruvate Dehydrogenase (PDH) and a-ketoglutarate dehydrogenase $(\mathrm{KGDH})[12,13]$, and thiamine improves the activity of these enzymes [13-15]. Thiamin pyrophosphate (TPP) inhibits PDH kinase, which phosphorylates and reduces PDH activity [16]. Thiamine deficiency reduces the activity of the thiamine dependent-enzymes KGDHC and $\mathrm{PDH}$ and also induces regional selective neurodegeneration [17-19]. Thiamine and TPP have been used in patients with PDH deficiency [20-24] and KGDH deficiency diseases [25-27]. Taken together, these findings suggest that there is a relationship between thiamine and Wilson's disease. Therefore, in this work, we review the role of thiamine in Wilson's disease.

\section{The Genomic Factors Associated with Thiamine In Cancer}

The $p 53$ gene and protein play a critical role in the regulation of the normal cell cycle, cell cycle arrest, and the apoptotic response. p53 is a transcription factor with a major role in determining cell fate in response to DNA damage. Treating human liver cells with copper, results in a significant elevation of p53 levels that is accompanied by evidence of apoptosis [28]. Copper induces apoptosis in epithelial breast cancer MCF-7 cells independently of the caspases, and a functional p53 is required for apoptosis in these epithelial cells [29]. Increased p53 mutations were observed in liver samples from patients with Wilson's disease [30], and an increased p53 mutation load was suggested to predispose individuals with Wilson's disease to the development of cancer [31]. However, increased Thiamine Transporter (ThTr) levels are observed in cells that over-express mThTr-1 or in cells that have been exposed to conditions that induce DNA damage or p53 activation [32]. Thiamine diphosphate (TDP) inhibits p53 binding, and thiamine inhibits intracellular p53 activity [33]. p53 expression is significantly decreased in cultured retinal neurons of diabetic rats treated with thiamine compared with controls [34]. These observations suggest that the transcription factor p53 is activated in Wilson's disease and show that there is an increasing apoptotic response to cellular damage. These observations also suggest that thiamine ameliorates these effects.

Bcl-2 is a membrane-bound protein that plays a neuron-protective role in the CNS. Bcl-2 inhibits apoptosis and enhances the survival of newborn neurons in the normal and ischemic hippocampus [35]. Bcl-2 mRNA and protein expression are developmentally regulated in both the human and murine brain [36,37]. Bcl-2 inhibits the death of a central neural cell line due to serum and growth factor withdrawal, the calcium ionophore A23187, glucose withdrawal, membrane peroxidation, and

*Corresponding author: Khanh vinh quoc Lương, Vietnamese American Medical Research Foundation, Westminster, California, USA, Tel: 714839 5898; Fax: 714 839 5989; E-mail: Lng2687765@aol.com

Received September 06, 2013; Accepted October 08, 2013; Published October 10, 2013

Citation: vinh quoc Lương K, Nguyen LTH (2013) The Role of Thiamine in Wilson's Disease: Possible Genetic and Cellular Signaling Mechanisms. J Mol Genet Med 7: 79. doi:10.4172/1747-0862.1000079

Copyright: (c) 2013 vinh quoc Lương $\mathrm{K}$, et al. This is an open-access article distributed under the terms of the Creative Commons Attribution License, which permits unrestricted use, distribution, and reproduction in any medium, provided the original author and source are credited 
in some cases, free-radical-induced damage [38]. Using human M17 neuroblastoma cells as a model to examine copper toxicity, copperglycine reduced $\mathrm{Bcl}-2$ expression by $50 \%$ compared with glycinetreated cells [39]. As excessive copper ingestion is further prolonged, copper levels in the liver and serum and the alanine aminotransferase (ALT) level in serum rise, and apoptotic cells appear in the liver. Bax and Bcl-2 expression significantly increase and progressively increase with further prolonged excessive copper ingestion in rat models of hepatolenticular degeneration compared with controls fed a normal diet [40]. However, pre-treatment with $B$ vitamins $\left(B_{1}, B_{6}\right.$, and $\left.B_{12}\right)$ has a protective effect in the brain of mice with experimentally induced epilepsy, with an early induction of Bcl-2 expression within 12 hours of the epileptic episode [41]. Thiamine deprivation increases cell death and reduces Bcl-2 expression during hybridoma cell culture [42]. Benfotiamine is a transketolase activator that directs glucose to the pentose phosphate pathway andimproves the functional recovery of an infarcted heart by increasing Bcl-2 protein levels [43]. When human and bovine pericytes are intermittently exposed to high glucose, there is a $50-60 \%$ decrease in the Bcl-2 to Bax ratio for both expression and concentration; the addition of thiamine and benfotiamine completely reverses this damaging effect [44]. Taken together, these findings suggest that thiamine may play a neuron-protective role in Wilson's disease by increasing the apoptotic inhibitor Bcl-2.

Caspases are cysteinyl aspartate-specific proteases that play a critical role in the regulatory and execution phases of apoptosis [45]. Increased caspase- 3 activity is consistently reported in the cortex of Long-Evans Cinnamon (LEC) rats [46]. The addition of $20 \mu \mathrm{M}$ copper for 22 hours to murine neocortical cell cultures decreases the ATP levels and induces neuronal death without glial death. This selective neuronal death is associated with the activation of caspase- 3 and is reduced by free radical scavengers; the addition of thiamine reduces copper-induced neuronal death [7]. Breast cancer cells transfected with the thiamine transporter SLC19A3 show an increase in apoptosis when exposed to doxorubicin and radiation, and the caspase-3-dependent pathway partially mediates this effect [47]. The thiamine deficiency caused by thiamine antagonists leads to caspase- 3 apoptosis in the neuronally differentiated rat PC-12 cell line [48]. Benfotiamine accelerates the healing of ischemic diabetic limbs in mice via the potentiation of angiogenesis and prevention of pro-apoptotic caspase-3 induction [49]. Sulbutiamine, a highly lipid-soluble synthetic analog of thiamine, attenuates trophic factor deprivation-induced cell death in transformed Retinal Ganglion Cells (RGC-5) and decreases the expression of cleaved caspase-3 [50]. These findings suggest that thiamine may play a role in Wilson's disease by inhibiting the activity of the apoptotic factor caspase-3.

Heme oxygenase-1 (HO-1) is a stress protein that may confer cytoprotection by enhancing the catabolism of pro-oxidant heme into the radical scavenging bile pigments biliverdin and bilirubin. The HO-1 gene is susceptible to up regulation by a host of noxious stimuli and is induced in CNS tissues that are affected by neurological diseases [51]. In a normal brain, the basal HO-1 expression level is low and is restricted to small groups of scattered neurons and neuroglia [52]. Exposure of hepatocellular carcinoma cell lines (HepG2 and Hep3B cells) to $\mathrm{Cu}^{2+}$ inhibits the enzymes porphobilinogen deaminase and aminolevulinate dehydratase of the heme synthesis pathway and, in parallel, upregulates HO-1 expression [53]. DL- $\alpha$-lipoic acid (LA) displays an antioxidant effect on copper-induced acute hepatitis in LEC rats; LA treatment significantly suppresses the inactivation of catalase and glutathione peroxidase and the induction of HO-1, which is inducible under oxidative stress. Furthermore, LA shows a dosedependent suppressive effect against the increase in the nonheme iron contents of both cytosolic and crude mitochondrial fractions [54]. Similarly, thiamine deficiency produces region-specific neuronal loss and HO- 1 induction in microglia $[55,56]$. Thiamine administration blocks further neuronal loss and the induction of HO-1-positive microglia (while other microglial changes persist) [57]. Taken together, these findings suggest that thiamine may play a role in Wilson's disease by suppressing $\mathrm{HO}-1$ expression.

In women, the apolipoprotein $E(A p o E)$ \&4-positive genotype is associated with an earlier onset of Wilson symptoms, particularly among $A T P$-ase $7 B$ gene p.H1069Q homozygous patients [58]. The presence of $A p o E \varepsilon 3 / 3$ attenuates clinical manifestations in European subjects with Wilson's disease [59]. However, Muramatsu et al. [60] reported that the frequency of the ApoE $\varepsilon 4$ allele is significantly higher in TD dementia patients. These findings suggest that the ApoE genotype may affect both Wilson's disease and thiamine status. Table 1 illustrates the genetic role of thiamine in Wilson's disease.

\section{The Role of Thiamine in Wilson's Disease}

Serotonin $(5-\mathrm{HT})$ is an indolamine that is derived from the amino acid tryptophan and is involved in a range of behaviors and psychological processes, including mood, anxiety, obsessivecompulsive symptoms, and social interaction. Free copper in the brain is toxic and leads to neuronal and cellular damage; copper reduces $\mathrm{N}$-acetyl transferase activity, which results in a decrease in $\mathrm{N}$-acetyl serotonin synthesis [61]. 5-HT immuno reactive fiber densities in the cingulate cortex, caudate-putamen, hypothalamus, and hippocampus in LEC rats are significantly higher than in controls at 4,10 , and 20 weeks of age. In the cingulate cortex and caudateputamen, 5-HT immunoreactive fiber densities gradually increase with age. The number of aberrant 5-HT immunoreactive fibers in the cingulate cortex, caudate-putamen, hypothalamus, and hippocampus of LEC rats is significantly higher than in controls [62]. In patients with Wilson's disease, depression is a frequent psychiatric symptom $[63,64]$. A prospective study revealed that depressive symptomatology is related to an alteration of presynaptic Serotonin Transporters (SERT) [65]. A significant negative correlation was found between the Hamilton rating scale for depression and SERT density in the thalamus-hypothalamus region of patients with Wilson's disease [66]. In addition, serotonergic system dysfunction occurs in mice fed with a TD diet; specifically, $\left[{ }^{3} \mathrm{H}\right] 5-\mathrm{HT}$, which labels the indolaminergic fiber systems of the cerebellum, medulla, mid-brain and diencephalon, was markedly decreased compared with mice that were fed normal chow [67]. The SSRI fluvoxamine significantly inhibits depressive behavior in TD mice, as measured by an increase of immobile time in a forced swimming test [68]. Patients with low cerebrospinal fluid thiamine concentrations exhibited low 5-Hydroxyindoleacetic Acid (5-HIAA) values; however, thiamine treatment increased 5-HIAA markedly [69]. There was a significant decrease in 5-HT uptake in the synaptosomal preparations of TD rat cerebella; the administration of thiamine in vivo resulted in a significant reverse of the inhibition of 5-HT uptake, which coincides with a dramatic clinical improvement [70]. A pyrithiamineinduced increase in the endogenous 5-HIAA of the medulla-pons region of TD rats occurs simultaneously with the onset of neurological signs; thiamine administration reverses both trends [71]. In addition, thiamine $(1-3,000 \mu \mathrm{M})$ reduces ${ }^{3} \mathrm{H}-5-\mathrm{HT}$ uptake to $83 \%$ of the control uptake levels in human placental choriocarcinoma cells. These cells are the only human cell line that expresses the 5-HT transporter [72]. Lurcher mice are characterized by considerable atrophy in the cerebellum, which is secondary to a massive loss of cerebellar Purkinje cells, granule cells, and neurons from the inferior olivary nucleus; a therapeutic combination of amantadine, thiamine, and L-tryptophan 


\section{Wilson's Disease}

p53 gene

${ }^{*}$ Copper results in a significant elevation of p53 levels, and human liver cells showed evidence of apoptosis.

*A p53 mutation was reported in samples of Wilson's disease.

${ }^{*}$ An increased p53 load was suggested to predispose individuals with Wilson's disease to the development of cancer.

$\mathrm{Bcl}-2$

${ }^{*} \mathrm{Bcl}-2$ is a membrane-bound protein that plays a neuro-protective role in the CNS.

${ }^{*} \mathrm{Bcl}-2$ inhibits apoptosis and enhances the survival of newborn neurons in the normal and ischemic hippocampus

*With a further prolonged excessive copper ingestion, copper levels in the liver and serum and the alanine aminotransferase level in serum rise, and more apoptotic cells appear in the liver.

\section{Caspases}

* Caspases are cysteinyl aspartate-specific proteases that play a critical role in the regulatory and execution phases of apoptosis.

*Increased caspase-3 activity is consistently reported in the cortex of Long-Evans Cinnamon (LEC) rats.

*The addition of $20 \mu \mathrm{M}$ copper for 22 hours to murine neocortical cell cultures decreases ATP levels, induces neuronal death, and is associated with caspase- 3 activation.

\section{Heme oxygenase-1 (HO-1)}

${ }^{\star}$ Exposure of hepatocellular carcinoma cell lines to $\mathrm{Cu}^{2+}$ upregulates $\mathrm{HO}-1$ expression.

* DL-a-lipoic acid (LA) has an antioxidant effect on copper-induced acute hepatitis in LEC rats. LA treatment significantly suppresses the induction of $\mathrm{HO}-1$.

\section{Apolipoprotein E (ApoE)}

*In women, the $A p o E \varepsilon 4$-positive genotype is associated with an earlie onset of Wilson symptoms, particularly among ATP-ase $7 B$ gene p.H1069Q homozygous patients.

*The presence of $A p o E \varepsilon 3 / 3$ attenuates clinical manifestations of Wilson's disease in European subjects.

\section{Thiamine}

* Increased thiamine transporter activity is observed in cells that over-express the genes that code for thiamine transporters and under conditions of DNA damage or p53 activation. *Thiamine diphosphate inhibits p53 binding, and thiamine inhibits intracellular p53 activity. *The expression of p53 decreases significantly in the cultured retinal neurons from diabetic rats treated with thiamine.

*Pre-treatment with $B$ vitamins $\left(B_{1}, B_{6}\right.$, and $\left.B_{12}\right)$ has a protective effect on experimental epilepsy in the brains of mice, with an early induction of Bcl-2 expression within 12 hours of the epileptic episode.

*Thiamine deprivation increases cell death and reduces Bcl-2 expression in cultured hybridoma cells.

*Benfotiamine improves the functional recovery of infarcted hearts, with increased Bcl-2 rotein levels.

The $\mathrm{Bcl}-2$ to Bax ratio decreases by $50 \%-60 \%$ (for both expression and concentration) in human and bovine pericytes that are intermittently exposed to high glucose; the addition of thiamine and benfotiamine completely reverses this damaging effect.

*Thiamine-transporter SLC19A3-transfected breast cancer cells show increased apoptosis when exposed to doxorubicin and radiation. The caspase-3-dependent pathway partially causes this increase.

*The thiamine deficiency caused by thiamine antagonists leads to caspase-3-induced apoptosis in neuronally differentiated rat PC-12 cells.

*Benfotiamine accelerates the healing of ischemic diabetic limbs in mice via the potentiation of angiogenesis and prevents the induction of pro-apoptotic caspase- 3 .

*Sulbutiamine, a highly lipid-soluble synthetic analog of thiamine, attenuates trophic factor deprivation-induced cell death in transformed retinal ganglion cells and decreases the expression of cleaved caspase-3.

*Thiamine deficiency produces region-specific neuronal loss and $\mathrm{HO}-1$ induction in microglia. *Thiamine administration blocks further neuronal loss and the induction of $\mathrm{HO}-1$-positive microglia.

${ }^{*}$ The frequency of the $A p o E \varepsilon 4$ allele is significantly higher in thiamine-deficient dementia patients.

Table 1: Genetic Factors Related to Thiamine and Wilson's disease.

increases SERT densities to $98 \%$ in Lurcher mice, which is higher than the densities of wild-type mice [73]. Taken together, these findings suggest that thiamine may modulate 5-HT in patients with Wilson's disease.

ROS play a major role in various cell signaling pathways. ROS activate various transcription factors and increase the expression of proteins that control cellular transformation, tumor cell survival, tumor cell proliferation and invasion, angiogenesis, and metastasis [74]. Among metals, copper is the most potent inducer of ROS production and apoptosis. Exposure to copper leads to a time-and dose-dependent increase in ROS generation [29]. ROS accumulation upon exposure to copper in three aquatic hyphomycete species is associated with nuclear morphological alterations, chromatin condensation, caspase-like activity, and DNA strand breaks [75]. When cultured astrocytes and neurons are treated with $20 \mu \mathrm{M}$ copper, copper causes death (42\%) in astrocytes within 48 hours; this effect can be reduced by antioxidants (35-60\% less death than in copper-treated cells) [76]. Lipid peroxidation-induced etheno-DNA adducts have been reported in the liver of patients with Wilson's disease [77]. Thus, the etheno adducts have been implicated as initiating DNA damage in copper/iron-induced carcinogenesis in humans. Malondialdehyde levels are higher in children with Wilson's disease than in controls [78]. A decrease of protein thiols, glutathione, and nitrogen species is associated with increased lipid peroxidation in the liver and striatum of LEC rats (a rodent model of Wilson's disease), and total SuperoxideDismutase (SOD) is consistently increased only in the cortex of LEC rats [46]. Enhanced Mn-SOD immunoreactivity has also been reported in the dopaminergic neurons of LEC rats [79]. However, oxidative stress has been associated with region-specific neuronal death, and lipid peroxidation products accumulate in the remaining thalamic neurons after 11 days of thiamine deficiency in animal models [80]. In vitro, thiamine inhibits lipid peroxidation in rat liver microsomes and free radical oxidation of oleic acid [81]. Thiamin rescues hepatocytes from iron-catalyzed oxidative stress by decreasing lipid peroxidation, mitochondrial and protein damage, and DNA oxidation [82]. Taken together, these findings suggest that thiamine modulates oxidative stress in Wilson's disease.

Nitric Oxide Synthase (NOS) is an enzyme that is involved in the synthesis of Nitric Oxide (NO), which regulates a variety of important physiological responses, including cell migration, the immune response, and apoptosis. Culturing astrocytes and neurons with $20 \mu \mathrm{M}$ copper causes neuronal death; this neurotoxicity can be prevented by antioxidants and NOS inhibitors [79]. When compared with liver samples from normal controls, $60 \%$ of patients with Wilson's disease show a higher expression of inducible NOS in the liver [31], suggesting that NO is a source of increased oxidative stress. The level of NO is higher in children with Wilson's disease compared with healthy children $[78,83]$. However, increased brain endothelial NOS expression is observed in response to thiamine deficiency [84]. In murine macrophages, benfotiamine also blocks the expression of inducible NOS by lipopolysaccharide-induced cytotoxicity [85]. These findings suggest that thiamine may modulate reactive nitrogen intermediates in patients with Wilson's disease. Table 2 illustrates the role of thiamine in Wilson's disease. 
Citation: vinh quoc Lương K, Nguyen LTH (2013) The Role of Thiamine in Wilson's Disease: Possible Genetic and Cellular Signaling Mechanisms. J Mol Genet Med 7: 79. doi:10.4172/1747-0862.1000079

Page 4 of 6

\section{Wilson's disease}

Serotonin (5-HT)

*5-HT immunoreactive fiber densities in the cingulate cortex, caudate-putamen, hypothalamus, and hippocampus in Long-Evans Cinnamon rats were significantly higher than the densities of controls at 4,10 , and 20 weeks of age.

*The number of aberrant 5-HT immunoreactive fibers in the cingulate cortex, caudate-putamen, hypothalamus, and hippocampus in LEC rats was significantly higher than in controls.

* In patients with Wilson's disease, depression is a frequent psychiatric symptom. A prospective study revealed that depressive symptomatology is related to an alteration of presynaptic serotonin transporters.

${ }^{*}$ A significant negative correlation was found between the Hamilton rating scale for depression and SERT density in the thalamus-hypothalamus region in patients with Wilson's disease.

\section{Reactive oxygen Species (ROS)}

*Exposure to copper leads to an increase in ROS generation

${ }^{*} \mathrm{ROS}$ accumulation upon exposure to copper in three aquatic hyphomycete species is associated

with the occurrence of nuclear morphological alterations, chromatin condensation, caspase-like activity and DNA strand breaks.

*Malondialdehyde levels were higher in Wilson's disease in childhood than in controls.

*A decrease of protein-thiols, glutathione and nitrogen species were associated with increased lipid

peroxidation in the liver and striatum of Long-Evans Cinnamon (LEC) rats (a rodent model of Wilson's

disease), and total superoxide-dismutase (SOD) consistently increased only in the cortex of LEC rats. *Enhanced Mn-SOD immunoreactivity was also reported in the dopaminergic neurons of LEC rats

\section{Nitric oxide synthetase (NOS)}

"Cultured astrocytes and neurons were treated with $20 \mu \mathrm{M}$ copper, which caused neuronal death and this neurotoxicity was prevented by antioxidants and NOS inhibitors.

*When compared with the liver samples from normal controls, sixty percent of the patients with

Wilson's disease showed a higher expression of inducible NOS in the live.

*NO level was higher in children with Wilson's disease compared to healthy children.

\section{Thiamine}

*Serotonergic system dysfunction occurs in thiamine-deficient (TD) mice.

*Selective serotonin reuptake inhibitors (SSRIs) significantly inhibits depressive behavior in TD mice.

${ }^{*}$ A significant decrease in 5-HT uptake in synaptosomal preparations of the cerebella of TD rats. Thiamine administration results in a significant reverse of the inhibition of 5-HT uptake.

*Lipid peroxidation product accumulates in the remaining thalamic neurons in TD animal models.

*Thiamine inhibits lipid peroxidation and free radical oxidation of oleic acid in rat liver microsomes.

Table 2: Role of thiamine in Wilson's disease.

\section{Conclusion}

The relationship between thiamine and Wilson's disease is discussed. Genetic studies have provided opportunities to determine which proteins may link thiamine to the pathology of Wilson's disease, including gene $\mathrm{p} 53, \mathrm{Bcl}-2$, caspase-3,HO-1, and ApoE. Thiamine can also act through a number of non-genomic mechanisms, including protein expression, 5-HT, oxidative stress, inflammation, and cellular metabolism. Thiamine supplementation has demonstrated the beneficial role of thiamine in patients with Wilson's disease. Therefore, further investigations on thiamine in Wilson's disease are needed. A more cautious approach would be advisable prior to recommending the widespread use of thiamine in patients with Wilson's disease.

\section{Acknowledgement}

Conflict of interest statement: The authors declare that they have no competing interests.

\section{References}

1. Huster D (2010) Wilson disease. Best Pract Res Clin Gastroenterol 24: 531 539 .

2. Litwin T, Gromadzka G, Szpak GM, Jabłonka-Salach K, Bulska E, et al. (2013) Brain metal accumulation in Wilson's disease. J Neurol Sci 329: 55-58.

3. Xu SQ, Zhu HY, Lin JG, Su TF, Liu Y, et al. (2013) Copper ions stimulate the proliferation of hepatic stellate cells via oxygen stress in vitro. J Huazhong Univ Sci Technolog Med Sci 33: 75-80.

4. Merle U, Eisenbach C, Weiss KH, Tuma S, Stremmel W (2009) Serum ceruloplasmin oxidase activity is a sensitive and highly specific diagnostic marker for Wilson's disease. J Hepatol 51: 925-930.

5. Rodionov IA (1975) Glycoproteins in rat blood serum and tissues and thiamine saturation of the body. Vopr Med Khim 21: 245-249.

6. Stepuro II, Piletskaya TP, Stepuro VI, Maskevich SA (1997) Thiamine oxidative transformations catalyzed by copper ions and ascorbic acid. Biochemistry (Mosc) 62: 1409-1414.

7. Sheline CT, Choi EH, Kim-Han JS, Dugan LL, Choi DW (2002) Cofactors of mitochondrial enzymes attenuate copper-induced death in vitro and in vivo. Ann Neurol 52: 195-204.
8. Tchounwou PB, Newsome C, Williams J, Glass K (2008) Copper-Induced Cytotoxicity and Transcriptional Activation of Stress Genes in Human Liver Carcinoma (HepG(2)) Cells. Met lons Biol Med 10: 285-290.

9. Tassabehji NM, VanLandingham JW, Levenson CW (2005) Copper alters the conformation and transcriptional activity of the tumor suppressor protein p53 in human Hep G2 cells. Exp Biol Med (Maywood) 230: 699-708.

10. Sheline CT (2011) Thiamine supplementation attenuated hepatocellular carcinoma in the Atp7b mouse model of Wilson's disease. Anticancer Res 31 3395-3399.

11. Sokol RJ, Twedt D, McKim JM Jr, Devereaux MW, Karrer FM, et al. (1994) Oxidant injury to hepatic mitochondria in patients with Wilson's disease and Bedlington terriers with copper toxicosis. Gastroenterology 107: 1788-1798.

12. Bogaert YE, Rosenthal RE, Fiskum G (1994) Postischemic inhibition of cerebral cortex pyruvate dehydrogenase. Free Radic Biol Med 16: 811-820.

13. Humphries KM, Szweda LI (1998) Selective inactivation of alpha-ketoglutarate dehydrogenase and pyruvate dehydrogenase: reaction of lipoic acid with 4-hydroxy-2-nonenal. Biochemistry 37: 15835-15841.

14. Sheline CT, Choi DW (2004) Cu2+ toxicity inhibition of mitochondrial dehydrogenases in vitro and in vivo. Ann Neurol 55: 645-653.

15. Brown A, Nemeria N, Yi J, Zhang D, Jordan WB, et al. (1997) 2-Oxo-3-alkynoic acids, universal mechanism-based inactivators of thiamin diphosphatedependent decarboxylases: synthesis and evidence for potent inactivation of the pyruvate dehydrogenase multienzyme complex. Biochemistry 36: 80718081.

16. Robertson JG, Barron LL, Olson MS (1990) Bovine heart pyruvate dehydrogenase kinase stimulation by alpha-ketoisovalerate. J Biol Chem 265 16814-16820.

17. Shi Q, Karuppagounder SS, Xu H, Pechman D, Chen H, Gibson GE (2007) Responses of the mitochondrial alpha-ketoglutaratedehydrogenase complex to thiamine deficiency may contribute to regional selective vulnerability. Neurochem Int 50: 921-931.

18. Bubber P, Ke ZJ, Gibson GE (2004) Tricarboxylic acid cycle enzymes following thiamine deficiency. Neurochem Int 45: 1021-1028.

19. Pannunzio P, Hazell AS, Pannunzio M, Rao KV, Butterworth RF (2000) Thiamine deficiency results in metabolic acidosis and energy failure in cerebellar granule cells: an in vitro model for the study of cell death mechanisms in Wernicke's encephalopathy. J Neurosci Res 62: 286-292.

20. Singhi P, De Meirleir L, Lissens W, Singhi S, Saini AG (2013) Pyruvate 
Citation: vinh quoc Lương K, Nguyen LTH (2013) The Role of Thiamine in Wilson's Disease: Possible Genetic and Cellular Signaling Mechanisms. J Mol Genet Med 7: 79. doi:10.4172/1747-0862.1000079

Page 5 of 6

dehydrogenase-e1 $\alpha$ deficiency presenting as recurrent demyelination: an unusual presentation and a novel mutation. JIMD Rep 10: 107-111.

21. Giribaldi G, Doria-Lamba L, Biancheri R, Severino M, Rossi A, et al. (2012) Intermittent-relapsing pyruvatedehydrogenase complex deficiency: a case with clinical, biochemical, and neuroradiological reversibility. Dev Med Child Neurol 54: $472-476$

22. Kohda Y, Umeki M, Kono T, Terasaki F, Matsumura H, et al. (2010) Thiamine ameliorates diabetes-induced inhibition of pyruvatedehydrogenase (PDH) in rat heart mitochondria: investigating the discrepancy between PDH activity and PDH E1alpha phosphorylation in cardiac fibroblasts exposed to high glucose. $J$ Pharmacol Sci 113: 343-352.

23. Sedel F, Challe G, Mayer JM, Boutron A, Fontaine B, et al. (2008) Thiamine responsive pyruvate dehydrogenase deficiency in an adult with peripheral neuropathy and optic neuropathy. J Neurol Neurosurg Psychiatry 79: 846-847.

24. Lee EH, Ahn MS, Hwang JS, Ryu KH, Kim SJ, et al. (2006) A Korean female patient with thiamine-responsive pyruvate dehydrogenase complex deficiency due to a novel point mutation (Y161C)in the PDHA1 gene. J Korean Med Sc 21: 800-804.

25. Mayr JA, Freisinger P, Schlachter K, Rolinski B, Zimmermann FA, et al. (2011) Thiamine pyrophosphokinase deficiency in encephalopathic children with defects in the pyruvate oxidation pathway. Am J Hum Genet 89: 806-812.

26. Abboud MR, Alexander D, Najjar SS (1985) Diabetes mellitus, thiaminedependent megaloblastic anemia, and sensorineural deafness associated with deficient alpha-ketoglutaratedehydrogenase activity.J Pediatr107: 537-541.

27. Kuroda Y, Kline JJ, Sweetman L, Nyhan WL, Groshong TD (1979) Abnorma pyruvate and alpha-ketoglutarate dehydrogenase complexes in a patient with lactic acidemia. Pediatr Res 13: 928-931.

28. Narayanan VS, Fitch CA, Levenson CW (2001) Tumor suppressor protein p53 mRNA and subcellular localization are altered by changes in cellular copper in human Hep G2 cells. J Nutr 131: 1427-1432.

29. Ostrakhovitch EA, Cherian MG (2005) Role of p53 and reactive oxygen species in apoptotic response to copper and zinc in epithelial breast cancer cells. Apoptosis 10: 111-121.

30. Milacic V, Chen D, Giovagnini L, Diez A, Fregona D, et al. (2008) Pyrrolidine dithiocarbamate-zinc(II) and -copper(II) complexes induce apoptosis in tumor cells by inhibiting the proteasomal activity. Toxicol Appl Pharmacol 231: 24-33.

31. Hussain SP, Raja K, Amstad PA, Sawyer M, Trudel LJ, et al. (2000) Increased p53 mutation load in nontumorous human liver of wilson disease and hemochromatosis: oxyradical overload diseases. Proc Natl Acad Sci U S A 97: 12770-12775.

32. Lo PK, Chen JY, Tang PP, Lin J, Lin CH, et al. (2001) Identification of a mouse thiamine transporter gene as a direct transcriptional target for p53. J Biol Chem 276: 37186-37193.

33. McLure KG, Takagi M, Kastan MB (2004) NAD+ modulates p53 DNA binding specificity and function. Mol Cell Biol 24: 9958-9967.

34. Yang Z, Ge J, Yin W, Shen H, Liu H, et al. (2004) The expression of p53, MDM2 and Ref1 gene in cultured retina neurons of SD rats treated with vitamin B1 and/or elevated pressure. Yan Ke Xue Bao 20: 259-263.

35. Sasaki T, Kitagawa K, Yagita Y, Sugiura S, Omura-Matsuoka E, et al. (2006) $\mathrm{Bcl} 2$ enhances survival of newborn neurons in the normal and ischemic hippocampus. J Neurosci Res 84: 1187-1196.

36. Jarskog LF, Gilmore JH (2000) Developmental expression of $\mathrm{Bcl}-2$ protein in human cortex. Brain Res Dev Brain Res 119: 225-230.

37. Shimohama S, Fujimoto S, Sumida Y, Tanino H (1998) Differential expression of rat brain bcl-2 family proteins in development and aging. Biochem Biophys Res Commun 252: 92-96.

38. Zhong LT, Sarafian T, Kane DJ, Charles AC, Mah SP, et al. (1993) bcl-2 inhibits death of central neural cells induced by multiple agents. Proc Natl Acad Sci U S A 90: 4533-4537.

39. Chan HW, Liu T, Verdile G, Bishop G, Haasl RJ, et al. (2008) Copper Induces Apoptosis of Neuroblastoma Cells Via Post-translational Regulation of the Expression of Bcl-2-family Proteins and the tx Mouse is a Better Model of Hepatic than Brain Cu Toxicity. Int J Clin Exp Med 1: 76-88.

40. Li YW, Wang XH, Nin Q, Luo XP (2008) Excessive copper induces hepatocyte apoptosis and affects Bax and Bcl-2 expression in rat liver. Zhongguo Dang Dai Er Ke Za Zhi 10: 42-46.

41. Rabie T, Mühlhofer W, Bruckner T, Schwab A, Bauer AT, et al. (2010) Transient protective effect of B-vitamins in experimental epilepsy in the mouse brain. J Mol Neurosci 41: 74-79.

42. Ishaque A, Al-Rubeai M (2002) Role of vitamins in determining apoptosis and extent of suppression by bcl-2 during hybridoma cell culture. Apoptosis 7: 231239.

43. Katare R, Caporali A, Emanueli C, Madeddu P (2010) Benfotiamine improves functional recovery of the infarcted heart via activation of pro-survival G6PD/ Akt signaling pathway and modulation of neurohormonal response. J Mol Cell Cardiol 49: 625-638.

44. Beltramo E, Berrone E, Tarallo S, Porta M (2009) Different apoptotic response of human and bovine pericytes to fluctuating glucose levels and protective role of thiamine. Diabetes Metab Res Rev 25: 566-576.

45. Salvesen GS, Riedl SJ (2008) Caspase mechanisms. Adv Exp Med Biol 615 13-23

46. Samuele A, Mangiagalli A, Armentero MT, Fancellu R, Bazzini E, et al. (2005) Oxidative stress and pro-apoptotic conditions in a rodent model of Wilson's disease. Biochim Biophys Acta 1741: 325-330.

47. Liu S, Huang H, Lu X, Golinski M, Comesse S, et al. (2003) Down-regulation of thiamine transporter THTR2 gene expression in breast cancer and its association with resistance to apoptosis. Mol Cancer Res 1: 665-673.

48. Chornyy S, Parkhomenko J, Chorna N (2007) Thiamine deficiency caused by thiamine antagonists triggers upregulation of apoptosis inducing facto gene expression and leads to caspase 3-mediated apoptosis in neuronally differentiated rat PC-12 cells. Acta Biochim Pol 54: 315-322.

49. Gadau S, Emanueli C, Van Linthout S, Graiani G, Todaro M, et al. (2006) Benfotiamine accelerates the healing of ischaemic diabetic limbs in mice through protein kinase B/Akt-mediated potentiation of angiogenesis and inhibition of apoptosis. Diabetologia 49: 405-420.

50. Kang KD, Majid AS, Kim KA, Kang K, Ahn HR, et al. (2010) Sulbutiamine counteracts trophic factor deprivation induced apoptotic cell death in transformed retinal ganglion cells. Neurochem Res 35: 1828-1839.

51. Hascalovici JR, Vaya J, Khatib S, Holcroft CA, Zukor H, et al. (2009) Brain sterol dysregulation in sporadic $A D$ and $\mathrm{MCl}$ : relationship to heme oxygenase-1. J Neurochem 110: 1241-1253.

52. Barañano DE, Snyder SH (2001) Neural roles for heme oxygenase: contrasts to nitric oxide synthase. Proc Natl Acad Sci U S A 98: 10996-11002.

53. Hait-Darshan R, Babushkin T, Malik Z (2009) Regulation of heme synthesis and proteasomal activity by copper: possible implications for Wilson's disease. J Environ Pathol Toxicol Oncol 28: 209-221.

54. Yamamoto H, Watanabe T, Mizuno H, Endo K, Fukushige J, et al. (2001) The antioxidant effect of DL-alpha-lipoic acid on copper-induced acute hepatitis in Long-Evans Cinnamon (LEC) rats. Free Radic Res 34: 69-80.

55. Calingasan NY, Gibson GE (2000) Dietary restriction attenuates the neurona loss, induction of heme oxygenase-1 and blood-brain barrier breakdown induced by impaired oxidative metabolism. Brain Res 885: 62-69.

56. Beauchesne E, Desjardins P, Hazell AS, Butterworth RF (2009) eNOS gene deletion restores blood-brain barrier integrity and attenuates neurodegeneration in the thiamine-deficient mouse brain. J Neurochem 111: 452-459.

57. Ke ZJ, DeGiorgio LA, Volpe BT, Gibson GE (2003) Reversal of thiamine deficiency-induced neurodegeneration. J Neuropathol Exp Neurol 62: 195-207.

58. Litwin T, Gromadzka G, CzÅ,onkowska A (2012) Apolipoprotein E gene (APOE) genotype in Wilson's disease: impact on clinical presentation. Parkinsonism Relat Disord 18: 367-369.

59. Schiefermeier M, Kollegger H, Madl C, Polli C, Oder W, et al. (2000) The impact of apolipoprotein $\mathrm{E}$ genotypes on age at onset of symptoms and phenotypic expression in Wilson's disease. Brain $123 \mathrm{Pt}$ 3: 585-590.

60. Muramatsu T, Kato M, Matsui T, Yoshimasu H, Yoshino A, et al. (1997) Apolipoprotein E epsilon 4 allele distribution in Wernicke-Korsakoff syndrome with or without global intellectual deficits. J Neural Transm 104: 913-920.

61. Parmar P, Daya S (2001) The effect of copper on (3H)-tryptophan metabolism in organ cultures of rat pineal glands. Metab Brain Dis 16: 199-205. 
Citation: vinh quoc Lương K, Nguyen LTH (2013) The Role of Thiamine in Wilson's Disease: Possible Genetic and Cellular Signaling Mechanisms. J Mol Genet Med 7: 79. doi:10.4172/1747-0862.1000079

62. Kawano H, Takeuchi Y, Yoshimoto K, Matsumoto K, Sugimoto T (2001) Histological changes in monoaminergic neurons of Long-Evans Cinnamon rats. Brain Res 915: 25-31.

63. Dening TR, Berrios GE (1989) Wilson's disease. Psychiatric symptoms in 195 cases. Arch Gen Psychiatry 46: 1126-1134.

64. Akil M, Brewer GJ (1995) Psychiatric and behavioral abnormalities in Wilson's disease. Adv Neurol 65: 171-178.

65. Hesse S, Barthel H, Hermann W, Murai T, Kluge R, et al. (2003) Regional serotonin transporter availability and depression are correlated in Wilson's disease. J Neural Transm 110: 923-933.

66. Eggers B, Hermann W, Barthel H, Sabri O, Wagner A, et al. (2003) The degree of depression in Hamilton rating scale is correlated with the density of presynaptic serotonin transporters in 23 patients with Wilson's disease. J Neurol 250: 576-580.

67. Chan-Palay V, Plaitakis A, Nicklas W, Berl S (1977) Autoradiographic demonstration of loss of labeled indoleamine axons of the cerebellum in chronic diet-induced thiamine deficiency. Brain Res 138: 380-384

68. Murata A, Nakagawasai O, Yamadera F, Oba A, Wakui K, et al. (2004) Dysfunction of serotonergic systems in thiamine-deficient diet fed mice: effects of SSRI on abnormality induced by thiamine deficiency. Nihon Shinkei Seishin Yakurigaku Zasshi 24: 93-99.

69. Botez MI, Young SN, Bachevalier J, Gauthier S (1982) Thiamine deficiency and cerebrospinal fluid 5-hydroxyindoleacetic acid: a preliminary study. J Neurol Neurosurg Psychiatry 45: 731-733.

70. Plaitakis A, Nicklas WJ, Berl S (1978) Thiamine deficiency: selective impairment of the cerebellar serotonergic system. Neurology 28: 691-698.

71. Van Woert MH, Plaitakis A, Hwang EC, Berl S (1979) Effect of thiamine deficiency on brain serotonin turnover. Brain Res 179: 103-110.

72. Keating E, Lemos C, Monteiro R, Azevedo I, Martel F (2004) The effect of a series of organic cations upon the plasmalemmal serotonin transporter, SERT. Life Sci 76: 103-119.

73. Le Marec N, Hébert C, Botez MI, Botez-Marquard T, Marchand L, et al. (1999) Serotonin innervation of Lurcher mutant mice: basic data and manipulation with a combination of amantadine, thiamine and L-tryptophan. Brain Res Bull 48 195-201.
74. Gupta SC, Hevia D, Patchva S, Park B, Koh W, et al. (2012) Upsides and downsides of reactive oxygen species for cancer: the roles of reactive oxygen species in tumorigenesis, prevention, and therapy. Antioxid Redox Signal 16: 1295-1322.

75. Azevedo MM, Almeida B, Ludovico P, Cássio F (2009) Metal stress induces programmed cell death in aquatic fungi. Aquat Toxicol 92: 264-270.

76. Reddy PV, Rao KV, Norenberg MD (2008) The mitochondrial permeability transition, and oxidative and nitrosative stress in the mechanism of copper toxicity in cultured neurons and astrocytes. Lab Invest 88: 816-830.

77. Nair J, Carmichael PL, Fernando RC, Phillips DH, Strain AJ, et al. (1998) Lipid peroxidation-induced etheno-DNA adducts in the liver of patients with the genetic metal storage disorders Wilson's disease and primary hemochromatosis. Cancer Epidemiol Biomarkers Prev 7: 435-440.

78. Dalgiç B, Sönmez N, Biberoğlu G, Hasanoğlu A, Erbaş D (2005) Evaluation of oxidant stress in Wilson's disease and non-Wilsonian chronic liver disease in childhood. Turk J Gastroenterol 16: 7-11.

79. Dalgiç B, Sönmez N, Biberoğlu G, Hasanoğlu A, Erbaş D (2005) Evaluation of oxidant stress in Wilson's disease and non-Wilsonian chronic liver disease in childhood. Turk J Gastroenterol 16: 7-11.

80. Kim DW, Ahn TB, Kim JM, Jeon GS, Seo JH, et al. (2005) Enhanced Mn-SOD immunoreactivity in the dopaminergic neurons of long-evans cinnamon rats. Neurochem Res 30: 475-478.

81. Calingasan NY, Chun WJ, Park LC, Uchida K, Gibson GE (1999) Oxidative stress is associated with region-specific neuronal death during thiamine deficiency. J Neuropathol Exp Neurol 58: 946-958.

82. Lukienko PI, Mel'nichenko NG, Zverinskii IV, Zabrodskaya SV (2000) Antioxidant properties of thiamine. Bull Exp Biol Med 130: 874-876.

83. Mehta R, Dedina L, O'Brien PJ (2011) Rescuing hepatocytes from ironcatalyzed oxidative stress using vitamins B1 and B6. Toxicol In vitro 25: 1114 1122.

84. Selimoglu MA, Ertekin V, Turkan Y, Akcay F (2007) Serum nitric oxide levels in children with Wilson's disease. Int J Clin Pract 61: 1530-1534.

85. Yadav UC, Subramanyam S, Ramana KV (2009) Prevention of endotoxininduced uveitis in rats by benfotiamine, a lipophilic analogue of vitamin B1. Invest Ophthalmol Vis Sci 50: 2276-2282. 